\title{
BMJ Open Cross-sectional study about the use of telemedicine for type 2 diabetes mellitus management in Spain: patient's perspective. The EnREDa2 Study
}

\author{
Patricia Rodríguez-Fortúnez, ${ }^{1}$ Josep Franch-Nadal, ${ }^{2,3}$ José A Fornos-Pérez, ${ }^{4}$ \\ Fernando Martínez-Martínez, ${ }^{5}$ Hector David de Paz, ${ }^{6}$ María Luisa Orera-Peña ${ }^{1}$
}

To cite: Rodríguez-Fortúnez $\mathrm{P}$, Franch-Nadal J, FornosPérez JA, et al. Cross-sectional study about the use of telemedicine for type 2 diabetes mellitus management in Spain: patient's perspective. The EnREDa2 Study. BMJ Open 2019;9:e028467. doi:10.1136/ bmjopen-2018-028467

- Prepublication history and additional material for this paper are available online. To view these files, please visit the journal online (http://dx.doi. org/10.1136/bmjopen-2018028467).

Received 14 December 2018 Revised 3 June 2019 Accepted 4 June 2019
Check for updates

(C) Author(s) (or their employer(s)) 2019. Re-use permitted under CC BY-NC. No commercial re-use. See rights and permissions. Published by BMJ.

For numbered affiliations see end of article.

Correspondence to Dr Patricia Rodríguez-Fortúnez; patricia.rodriguez@scren.es

\section{ABSTRACT}

Objectives The usefulness of telemedicine (TM) in type 2 diabetes mellitus (T2DM) has been discussed in recent years. The aim of this study is to describe patients' perceptions about TM and to identify preferences on TM resources, in Spain.

Design An observational, cross-sectional study was conducted using a structured questionnaire.

Participants 1036 patients with T2DM accepted to participate in the study (response rate: 68\%).

Results Blood glucose values were recorded by $85.9 \%$ of the patients while data such as lifestyle habits were only recorded by $14.4 \%$ of the patients. Previous experience in TM was reported by $9.8 \%$ of the patients, out of which $70.5 \%$ were satisfied with its service and $73.5 \%$ considered that the use of TM had optimised their T2DM management. However, most of these patients noted aspects to be improved such as user-friendliness $(81.4 \%)$, interaction with the medical team $(78.4 \%)$ and time required for recording/transferring data $(78.4 \%)$. Experienced patients had better perception about TM usefulness than naïve patients for all listed aspects $(p<0.05)$. Among naïve patients, $38.2 \%$ expressed their willingness to participate in TM programmes, but only $4.7 \%$ were invited to do so. Patients considered that physicians' $(77.5 \%)$ and pharmacists' $(75.5 \%)$ encouragement can boost the use of TM.

Conclusions In Spain, nearly $10 \%$ of patients with T2DM have experience with TM and it is well accepted, especially one based on glucometers. Nevertheless, in order to promote TM use, easier and time-saving programmes for patient-physician interaction should be optimised.

\section{INTRODUCTION}

In Spain, the prevalence of type two diabetes mellitus (T2DM) is $13.8 \%(2010) .{ }^{1}$ T2DM is one of the most common global metabolic disorders and its prevalence is expected to increase in the coming years. ${ }^{2}$ The rise in patients with T2DM will contribute to an increase in the need for healthcare. ${ }^{3}$ New information and communication technologies (ICTs) can allow the exchange of data between physicians and patients to be

\section{Strengths and limitations of this study}

- This is one of the few recent studies that evaluate the prevalence and patient's preferences about the use of telemedicine TM in Spain with an important sample size.

- This study presents a number of limitations inherent in its observational design, including susceptibility to bias and confounding, which restrict the ability to define causality.

- In addition, the results must be interpreted while keeping in mind that all of the issues evaluated, including those related to the patient's clinical situation, are always expressed from the patient's point of view, which increases the possibility that the issues raised here may have different interpretations.

- Furthermore, snowball technique could lead to potential sampling bias and low sample representativeness.

- Nevertheless, the wide sample variability observed (clinical and sociodemographic) suggests a very limited bias.

faster and more fluid, and increase patients' involvement in the self-management of their disease. ${ }^{4}$ Similarly, they can make exchange information easier for medical specialists, avoiding the need for referral and reducing waiting lists. ${ }^{5-7}$ Thus, the use of health telematics to manage these conditions could improve the quality of healthcare for these patients. A number of studies support the use of telemedicine (TM) for chronic disease management, demonstrating how its use improves compliance with treatment recommendations, and reduces the time spent per visit and the generated costs. ${ }^{8-12}$

T2DM is one of the chronic diseases which can benefit the most from TM. The use of TM contributes to optimisation of glycaemic control. Thus, patients who use TM have shown a greater reduction of glycated haemoglobin (HbAlc) levels than those 
receiving usual care. ${ }^{1314}$ Moreover, the use of TM, at least in specific interventions, helps to optimise improvement of weight control, ${ }^{15}$ body mass index,${ }^{15}$ blood pressure,,${ }^{1617}$ low-density lipoprotein values, ${ }^{17} 18$ pain ${ }^{19}$ and to improve health-related quality of life. ${ }^{151920}$ At the same time, TM is a useful tool for reducing the number of visits to the doctor by patients with T2DM, thereby saving time and money on commutes. ${ }^{21-23}$

Although the use of TM has shown to have multiple benefits and policy makers and payers consider it to be of interest ${ }^{24}$ there are factors related to patients' trust ${ }^{25}$ and sociodemographic characteristics ${ }^{26}$ thatcan make its implementation for T2DM management difficult. The aim of this study is to describe and clarify the current situation in Spain regarding the use of TM by patients with T2DM, patients' perceptions about the benefits of using $\mathrm{TM}$ and their preferences for TM resources.

\section{SUBJECTS AND METHODS \\ Participants}

Patients $\geq 18$ years of age with T2DM of at least 1 year's duration were included. Patients from every Spanish region were selected using snowball sampling techniques. ${ }^{27}$ The initial participants were recruited from primary care of the Spanish Healthcare System from a diverse set of primary care offices. The physicians involved in the study had at least 2 years of clinical experience in T2DM management.

The population size was estimated assuming maximum indetermination, with a $99 \%$ CI and a $4 \%$ precision error margin. The adult Spanish population for 2015 (37007 $319)^{28}$ and T2DM prevalence in Spain $(13.8 \%)^{1}$ were considered. This resulted in a final planned sample size of 1036 patients.

\section{Study design}

A descriptive observational study was conducted from 18 April 2016 to 5 August 2016. An ad hoc questionnaire was designed after literature review about the use of TM for T2DM management and about patients' preferences for TM resources in Spain. A scientific committee of two expert physicians was involved in the questionnaire composition, which consisted of 48 questions divided into four sections: (1) sociodemographic variables, (2) patient-reported clinical variables, (3) matters related to the use of ICTs and TM resources and (4) patients' perceptions about the use of TM. This latter section distinguished between patients who had reported prior experience using TM and those who had none (naïve). TM was previously defined as the exchange of medical information to healthcare professionals via electronic communication. Open, closed-ended (dichotomous or multichoice) and 5-point Likert-scale questions comprised the survey (see online supplementary file). The survey was conducted online and by phone.

\section{Statistical analysis}

Statistical analysis was performed using STATA statistical software, V.14. In all statistical tests, $\mathrm{p}$ value $<0.05$ was considered to be statistically significant. No methods for handling with missing data were applied due to the high sample size and the small amount of missing data. Absolute and relative frequencies were calculated for qualitative variables. Means, SD and percentile distributions were used to describe quantitative variables. The $\chi^{2}$ test was used for comparing qualitative variables between groups while quantitative variables were compared using Student's t-test or the equivalent method for non-parametric variables (Mann-Whitney $\mathrm{U}$ test).

In addition, since the technology skills of the elderly tend to be less developed, ${ }^{29}$ a subanalysis of questions related to the use of ICTs based on patient's age $(<65 \mathrm{vs}$ $\geq 65$ years) was performed using the $\chi^{2}$ test.

For clarity, responses to Likert-scale questions have been grouped in three categories (clustering the extreme categories). However, the statistical analysis has been calculated with the disaggregated data (5-point Likert scale).

\section{Ethical considerations}

All the patients received information relevant to the study and gave their informed consent to participate. All documents were coded in order to ensure the confidentiality of the data. The results of this study will be published by an open access scientific journal and by a doctoral thesis.

\section{Patient and public involvement}

No patients were included in the design and planning of the study. Including patient and public involvement (PPI) statements aligns closely with BMJ Open's values of transparency and inclusiveness. We hope that including PPI statements in all articles is the first step of many for BMJ Open in encouraging patient's involvement.

\section{RESULTS}

\section{Description of the patients}

A total number of 1523 patients with T2DM were invited to participate in the study. Of them, 1036 participants, representative of all the autonomous communities, accepted to participate (rate of response: 68\%). When the minimum estimated sample was reached, recruitment was concluded. The mean age of the patients was 60.3 years, $50.5 \%$ were men and the majority resided in urban areas (table 1). The overwhelming majority of patients $(95.6 \%)$ were receiving some type of treatment for their T2DM, the most common being a combination of oral antidiabetic drugs (64.2\%) (table 2).

\section{Use of ICTs by patients with T2DM}

The vast majority of patients reported having access to ICTs in their homes: mobile or landline phone (97.5\%), internet access $(71.6 \%)$ and personal computers (PCs) $(67.4 \%)$.

\section{Searching for information}

Only a $14.3 \%$ of the patients searched for information about their T2DM on the internet frequently or very 
Table 1 Sociodemographic characteristics of the patients with T2DM

\begin{tabular}{|c|c|c|c|c|c|c|c|}
\hline & $\begin{array}{l}\text { Total } \\
(n=1036)\end{array}$ & $\begin{array}{l}E \\
(n=102)\end{array}$ & $\begin{array}{l}N \\
(n=934)\end{array}$ & $\begin{array}{l}\text { P value } \\
\text { (E vs } N)\end{array}$ & $\begin{array}{l}\text { NI } \\
(n=577)\end{array}$ & $\begin{array}{l}\text { I } \\
(n=357)\end{array}$ & $\begin{array}{l}\text { P value } \\
\text { (ND vs N) }\end{array}$ \\
\hline Age (median (SD)), years & $60.3(15.0)$ & $42.7(13.5)$ & $62.3(13.9)$ & $<0.001$ & $66.6(11.9)$ & $55.2(13.9)$ & $<0.001$ \\
\hline Men (\% (n)) & $50.5(523)$ & $58.8(60)$ & $49.6(463)$ & $\begin{array}{l}X^{2}(d f=1)=3.14 \\
p=0.076\end{array}$ & $44.5(257)$ & $57.7(206)$ & $\begin{array}{l}X^{2}(d f=1)=15.28 \\
p<0.001\end{array}$ \\
\hline \multicolumn{8}{|l|}{ Location (\% (n)) } \\
\hline Rural & $23.4(242)$ & $15.7(16)$ & $24.2(226)$ & $\begin{array}{l}X^{2}(d f=1)=4.38 \\
p=112\end{array}$ & $26.5(153)$ & $20.4(73)$ & $\begin{array}{l}X^{2}(d f=1)=5.21 \\
p=0.074\end{array}$ \\
\hline \multicolumn{8}{|l|}{ Marital status (n (\%)) } \\
\hline Single & $6.2(64)$ & $5.9(6)$ & $6.2(58)$ & \multirow{3}{*}{$\begin{array}{l}X^{2} \\
(d f=3)=16.81 \\
p=0.001\end{array}$} & $4.5(26)$ & $9.0(32)$ & \multirow{3}{*}{$\begin{array}{l}X^{2}(d f=3)=26.47 \\
p<0.001\end{array}$} \\
\hline Partnership/Married & $75.6(783)$ & $89.2(91)$ & $74.1(692)$ & & $71.6(413)$ & $78.2(279)$ & \\
\hline Separated/Divorced & $6.1(63)$ & $4.9(5)$ & $6.2(58)$ & & $6.4(37)$ & $5.9(21)$ & \\
\hline Primary school & $20.2(209)$ & $3.9(4)$ & $21.9(205)$ & \multirow{3}{*}{$\begin{array}{l}X^{2} \\
(d f=3)=50.03 \\
p<0.001\end{array}$} & $26.5(153)$ & $14.6(52)$ & \multirow{3}{*}{$\begin{array}{l}X^{2} \\
(d f=3)=111.91 \\
p<0.001\end{array}$} \\
\hline High school & $39.8(412)$ & $39.2(40)$ & $39.2(372)$ & & 39.7 (229) & $40.1(143)$ & \\
\hline University & $29.8(309)$ & $55.9(57)$ & $26.9(252)$ & & $17.0(98)$ & $43.1(154)$ & \\
\hline \multicolumn{8}{|l|}{ Employment status (\% (n)) } \\
\hline Student & $0.3(3)$ & $0.9(1)$ & $0.2(2)$ & \multirow{5}{*}{$\begin{array}{l}X^{2} \\
(d f=5)=50.03 \\
p<0.001\end{array}$} & $0.2(1)$ & $0.3(1)$ & \multirow{5}{*}{$\begin{array}{l}X^{2} \\
(d f=5)=165.38 \\
p<0.001\end{array}$} \\
\hline Currently employed & $35.8(371)$ & $81.4(83)$ & $30.8(288)$ & & $16.8(97)$ & $53.5(191)$ & \\
\hline Disabled & $1.8(19)$ & $2.9(3)$ & $1.7(16)$ & & $1.2(7)$ & $2.5(9)$ & \\
\hline Unemployed & $3.9(41)$ & $2.9(2)$ & $4.1(38)$ & & $2.8(16)$ & $6.2(22)$ & \\
\hline Retired & $39.0(404)$ & $7.8(8)$ & $42.4(396)$ & & $52.5(303)$ & $26.1(93)$ & \\
\hline
\end{tabular}

E, experienced; I, interested in TM; N, naïve; NI, not interested in TM; T2DM, type 2 diabetes mellitus; TM, telemedicine.

frequently, $32.3 \%$ did so once in a while and $53.4 \%$ never looked for information on internet. The most common searches were for T2DM-related complications $(51.6 \%)$, adverse reactions to treatment $(31.1 \%)$, characteristics of new treatments $(27.5 \%)$, appearance of hypoglycaemia $(21.5 \%)$ and changes to the treatment regimen $(20.1 \%)$. The devices that were most widely used for searching for this information were the computer (41.60\%), mobile phone $(17.47 \%)$ and personal digital assistant (PDA)/ tablet $(8.30 \%)$.

The most highly valued informational content on T2DM-related apps were information about medication $(54.4 \%)$, dose reminders $(47.4 \%)$, diet menu plans $(41.0 \%)$, calorie calculators $(35.4 \%)$ and physical activity metres $(34.8 \%)$.

Recording blood glucose levels and other variables

The majority of patients $(85.9 \%)$ recorded their blood glucose levels. Of the total of patients, the most commonly used formats for record keeping were paper $(33.6 \%)$, glucometer $(27.9 \%)$, PC $(10.3 \%)$ and mobile phone/PDA (4.9\%). The results of the subanalysis according to age showed significant differences. Patients aged $<65$ years used digital formats $\left(\mathrm{PC}: \mathrm{X}^{2}(\mathrm{df}=1)=61.64\right.$, $\mathrm{p}<0.001$; mobile phone $/$ PDA: $\mathrm{X}^{2}(\mathrm{df}=1)=33.24, \mathrm{p}<0.001$; glucometer: $\left.\mathrm{X}^{2}(\mathrm{df}=1)=15.59 ; \mathrm{p}<0.001\right)$ more often than did patients aged $\geq 65$ years (figure 1 ).

Other T2DM-related data, different from blood glucose levels, were recorded by $14.4 \%$ of patients. Of these, $51.0 \%$ kept record of their exercise sessions, $45.6 \%$ their calorie intake, $32.2 \%$ water intake, $21.4 \%$ HbAlc levels and $20.8 \%$ the number of hypoglycaemia episodes. Of the total patients, the format used to record these data were paper $(6.7 \%)$, followed by PC $(6.2 \%)$, glucometer $(4.9 \%)$ and mobile phone/PDA $(2.9 \%)$. Again, the use of digital formats was significantly greater among those who were $<65$ years of age $\left(\mathrm{PC}: \mathrm{X}^{2}(\mathrm{df}=1)=42.89, \mathrm{p}<0.001\right.$; mobile phone/PDA: $\mathrm{X}^{2}(\mathrm{df}=1)=9.43, \mathrm{p}=0.002$; glucometer: $\left.\mathrm{X}^{2}(\mathrm{df}=1)=0.53, \mathrm{p}=0.463\right)$ (figure 1$)$.

The data recorded were shared with the physician by $58.7 \%$ of patients, with the nurse $(23.3 \%)$ and the pharmacist $(5.9 \%)$, especially by patients under the age of 65 years (physicians: $\mathrm{X}^{2} \quad(\mathrm{df}=1)=5.20, \mathrm{p}=0.023$; nurse: $\mathrm{X}^{2}(\mathrm{df}=1)=0.03, \mathrm{p}=0.842$; pharmacists: $\mathrm{X}^{2} \quad(\mathrm{df}=1)=13.81$, $\mathrm{p}<0.001)$. In addition, $3.0 \%$ of the patients shared their data with other patients.

Use of TM in Spain

Small percentage of participants $(9.8 \%)$ had experience with TM. Compared with naïve patients, those with TM 
Table 2 Clinical characteristics of the patients with T2DM

Total

$(n=1.036)$

\begin{tabular}{ll}
\hline $\begin{array}{l}\text { Time for diagnosis }(\%(n)) \\
<5 \text { years }\end{array}$ & $28.4(294)$ \\
\hline $5-10$ years & $37.6(390)$ \\
\hline 10years & $33.9(352)$ \\
\hline Time from start of treatment $(\%(n))$ & \\
\hline 5 years & $33.1(328)$ \\
5-10years & $31.2(368)$ \\
$>10$ years & $29.7(294)$ \\
\hline Missing data & 46 \\
\hline
\end{tabular}

Type of T2DM treatment (\% (n))

\begin{tabular}{lc}
\hline Oral & $\mathbf{8 7 . 4}(\mathbf{9 0 6})$ \\
\hline Oral (monotherapy) & $4.5(4)$ \\
\hline Oral (combined treatment) & $64.2(582)$ \\
\hline Oral (fixed combination) & $31.2(283)$ \\
\hline Injectable (insulin) & $\mathbf{3 8 . 2 ( 3 9 6 )}$ \\
\hline Injectable (monotherapy) & $36.87(146)$ \\
\hline Injectable (combined treatment) & $63.13(250)$ \\
\hline Treatment adherence (\% (n)) & $64.00(663)$ \\
\hline T2DM-related health problems (\% (n)) & \\
\hline Diabetic foot & $8.49(88)$ \\
\hline Diabetic retinopathy & $14.67(152)$ \\
\hline Diabetic nephropathy & $11.39(118)$ \\
\hline Diabetic neuropathy & $19.88(206)$ \\
\hline Diabetic heart disease & $12.55(130)$ \\
Comorbidities (\% (n)) & \\
\hline Arterial hypertension & $46.81(485)$ \\
\hline Hypercholesterolaemia & $41.60(431)$ \\
\hline Hypertriglyceridaemia & $25.48(264)$ \\
\hline Obesity & $45.46(471)$ \\
\hline Repeated cystitis & $12.07(125)$ \\
\hline
\end{tabular}

T2DM, type 2 diabetes mellitus.

experience were significantly younger, had a higher level of education, were predominantly in active employment and lived with a partner (table 1). In addition, patients with insulin treatment had more experience in TM than those without insulin $\left(17.7 \%\right.$ vs $5.0 \% ; \mathrm{X}^{2}(\mathrm{df}=1)=44.28$; $\mathrm{p}<0.001)$.

Among patients who had no experience in TM, 38.2\% expressed a willingness to participate in TM programmes but only $4.7 \%$ had been invited to do so. Subanalysis by age ( $<65$ vs $\geq 65$ years) showed that most patients invited to participate were under age of 65 years $(3.2 \%$ vs $1.5 \%$; $\left.\mathrm{X}^{2} \quad(\mathrm{df}=1)=12.56 ; \mathrm{p}<0.001\right)$. Comparing patient who expressed interest in participating and those who did not, males (table 1$)$ and patients $<65$ years $(60.4 \%$ vs $21.9 \%$; $\left.\mathrm{X}^{2}(\mathrm{df}=1)=142.59 ; \mathrm{p}<0.001\right)$ were more interested in TM.
The TM resources that were most used by the patients were SMS/WhatsApp messages (45.1\%), telephone calls (42.9\%), glucometres with data transmission $(41.2 \%)$, online platform $(37.95 \%)$, mobile apps $(32.4 \%)$ and videoconferences $(6.9 \%)$ and those with a higher rate of satisfaction were glucometer $(100 \%)$, videoconferences (100\%) SMS/WhatsApp (97\%) and online platform $(97 \%)$.

\section{Perceptions of the benefits of using TM}

Patients felt that TM could reduce (quite a bit or a lot) the number of visits to the doctor $(47.7 \%)$, nurse (43.9\%), emergency room (39.9\%), pharmacy $(35.9 \%)$ and the time per visit $(43.2 \%)$. Compared with naive patients, the perceptions of patients with prior experience using TM was significantly more positive: visits to the doctor $\left(61.8 \%\right.$ vs $46.1 \%$; $\left.\mathrm{X}^{2}(\mathrm{df}=4)=14.83 ; \mathrm{p}=0.005\right)$, visits to the nurse $\left(59.8 \%\right.$ vs $42.2 \% ; \mathrm{X}^{2} \quad(\mathrm{df}=4)=15.88$; $\mathrm{p}=0.003)$, visits to the emergency room $(59.8 \%$ vs $37.7 \%$; $\left.\mathrm{X}^{2}(\mathrm{df}=4)=21.39 ; \mathrm{p}<0.001\right)$, visits to the pharmacy $(45.1 \%$ vs $\left.34.9 \% ; \mathrm{X}^{2}(\mathrm{df}=4)=16.13 ; \mathrm{p}=0.003\right)$ and time required for the doctor's visits $\left(63.7 \%\right.$ vs $41.0 \%$; $\mathrm{X}^{2}(\mathrm{df}=4)=38.51$; $\mathrm{p}<0.001$ ) (figure 2).

The majority of patients thought that TM could improve (quite a bit or a lot) all proposed aspects related to T2DM management, except for absences from work (figure 3). In comparison with naive patients, those with prior TM experience perceived TM provided greater benefits in the improvement of: knowledge about the disease $(78.4 \%$ vs $\left.60.9 \% ; \mathrm{p}=0.001 ; \mathrm{X}^{2}(\mathrm{df}=4)=18.64 ; \mathrm{p}=0.001\right)$, knowledge of the consequences of not adhering to treatment $\left(77.5 \%\right.$ vs $\left.54.7 \% ; \mathrm{X}^{2}(\mathrm{df}=4)=25.47 ; \mathrm{p}<0.001\right)$, adherence to treatment $\left(74.5 \%\right.$ vs $\left.54.6 \% ; \mathrm{X}^{2}(\mathrm{df}=4)=19.76 ; \mathrm{p}=0.001\right)$, observance of dietary recommendations $(67.6 \%$ vs $\left.55.6 \% ; \mathrm{X}^{2}(\mathrm{df}=4)=14.38 ; \mathrm{p}=0.006\right)$ and physical exercise recommendations $\left(76.5 \%\right.$ vs $53.1 \% ; \mathrm{X}^{2} \quad(\mathrm{df}=4)=25.47$; $\mathrm{p}<0.001)$, glycaemic control $(73.5 \%$ vs $58.7 \%$; $<<0.001$; $\left.\mathrm{X}^{2} \quad(\mathrm{df}=4)=20.15 ; \mathrm{p}<0.001\right)$, prevention of hypoglycaemic episodes $\left(77.5 \%\right.$ vs $56.9 \% ; \mathrm{X}^{2} \quad(\mathrm{df}=4)=22.18$; $\mathrm{p}<0.001)$, health-related quality of life $(78.4 \%$ vs $61.3 \%$; $\left.\mathrm{X}^{2}(\mathrm{df}=4)=16.36 ; \mathrm{p}=0.003\right)$ and the reduction of absences from work $\left(65.7 \%\right.$ vs $33.4 \% ; \mathrm{p}<0.001 ; \mathrm{X}^{2}(\mathrm{df}=4)=57.62$; $\mathrm{p}<0.001)$.

Most patients with TM experience $(73.6 \%)$ considered that the use of TM had optimised (quite a bit or a lot) the management of their T2DM.

\section{Preferences and satisfaction with TM}

With regard to their preferences for TM resources, the majority of patients with experience using TM showed quite a bit or a lot of interest in online platforms with content supervised by professionals $(70.6 \%)$, online platforms that allow communication with the medical team (70.6\%), mobile apps (70.6\%), SMS/WhatsApp reminders sent by the healthcare centre or pharmacy $(66.7 \%)$ and online platforms that allow them to communicate with other patients with similar health problems $(56.9 \%)$ (figure 4$)$. 
Blood glucose records

Other disease-related values

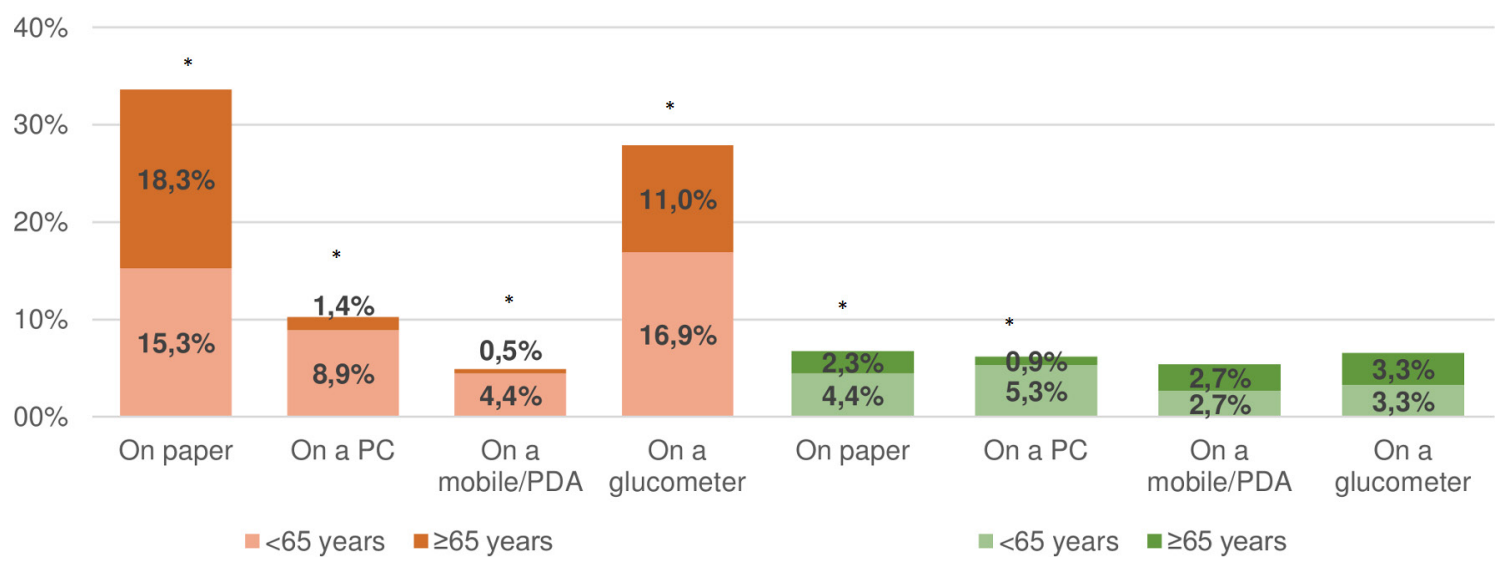

Figure 1 Percentage of patients who record their blood glucose levels and other type 2 diabetes mellitus-related data according to technology format and age group. ${ }^{*} \mathrm{P}<0.05$ ( $\chi^{2}$ test). PC, personal computer; PDA, personal digital assistant.

The percentage of patients who were satisfied or very satisfied with the use of TM for the management of their T2DM was $70.5 \%$, and $72.5 \%$ would participate again in another TM programme.

Improving and promoting TM

Participants who had prior TM experience were asked about possible improvement features. They indicated that it would be necessary or very necessary to improve certain issues, such as explanations about the programmes to help make them easier to use $(81.4 \%)$, interaction with the medical team $(78.4 \%)$, time required for recording/ transferring data $(78.4 \%)$, content $(76.5 \%)$, devices available $(74.5 \%)$, access to devices at the healthcare centre $(72.6 \%)$, interaction with other patients $(62.8 \%)$ and app design $(64.7 \%)$ (figure 5$)$.

Furthermore, $80.4 \%$ of patients would recommend the use of TM. However, in order to boost its use, they considered the following issues to be important: support from a health professional or experienced patient (79.4\%), simple instructions $(78.4 \%)$, recommendations for its use by the physician $(77.5 \%)$ or pharmacist $(75.5 \%)$, availability of the information that is recorded $(77.5 \%)$, recommendations for its use by friends or relatives $(69.6 \%)$ and television advertising $(58.8 \%)$.

\section{DISCUSSION}

There is a widespread adoption and use of ICT devices by Spanish households. In 2016, according to the Spanish National Statistics Institute, $81.9 \%$ of Spanish households had access to the internet, $96.7 \%$ to a mobile phone and $77.1 \%$ had a computer or similar device. ${ }^{30}$ These data are similar to those observed in our study, with the exception of the availability of computers, which in this case was $67.4 \%$.



Figure 2 Distribution of patients according to their perceptions about how telemedicine may reduce the use of healthcare resources. E, experienced; $N$, naïve; $T$, total. ${ }^{*} \mathrm{P}<0.05$ ( $\chi^{2}$ test; $4 \mathrm{df}$ ). 


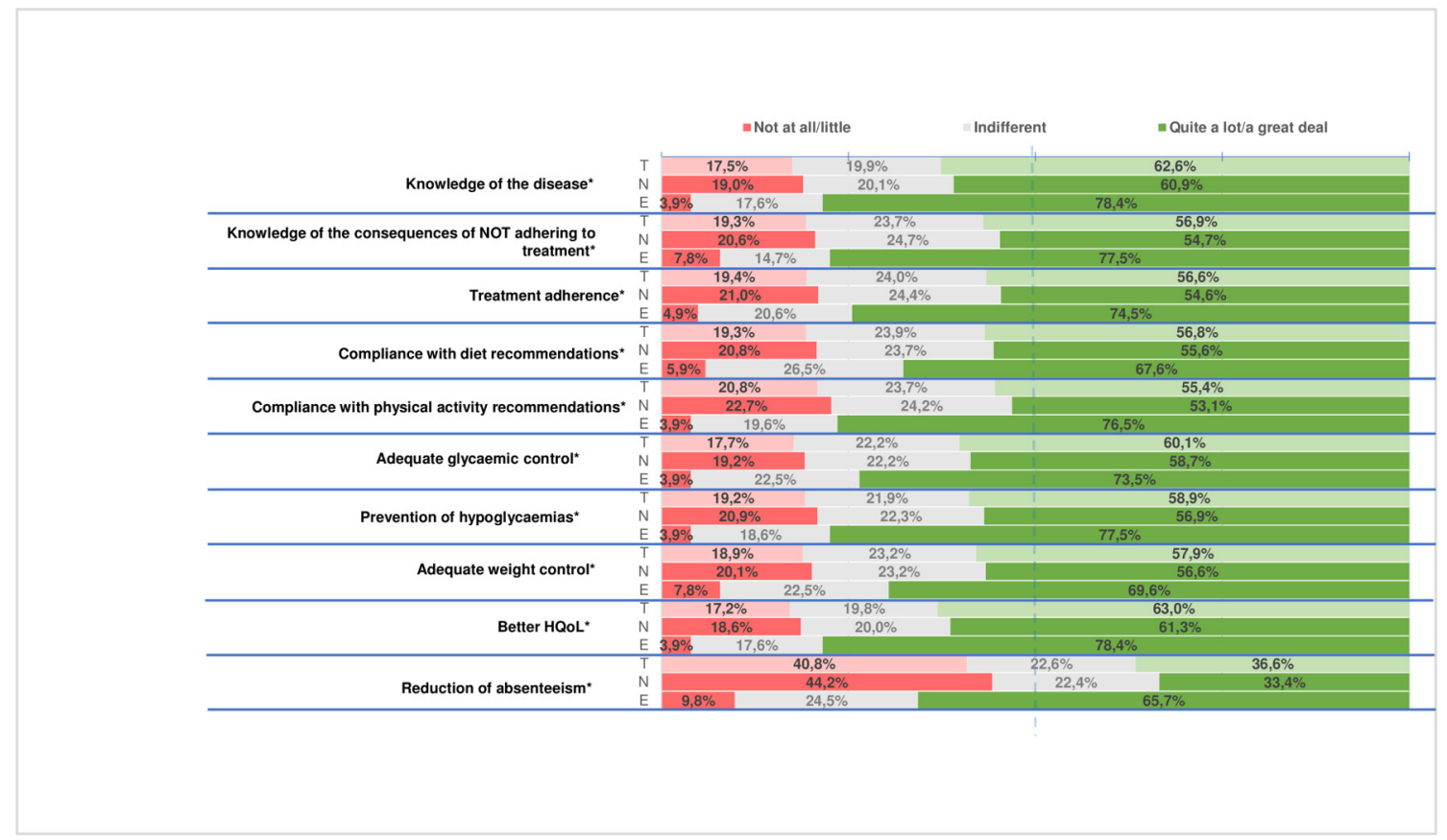

Figure 3 Distribution of patients according to their perceptions about how telemedicine may improve different aspects related to the management of type 2 diabetes mellitus. E, experienced; HRQoL, health-related quality of life; $\mathrm{N}$, naïve; T, total. ${ }^{*} \mathrm{P}<0.05$ $\left(\chi^{2}\right.$ test; $\left.4 \mathrm{df}\right)$.

Internet usage by patients to search for information about their disease has risen over the last decade, increasing from $23.9 \%$ in $2004^{31}$ to $66.9 \%$ in $2009 .{ }^{32}$ For T2DM, a study conducted in 203 patients showed that $28.1 \%$ of these patients searched for information on the internet about their disease. ${ }^{33}$ In contrast, in our study $46.6 \%$ of the patients reported to search information on the internet. In any case, it is apparent that to a greater or lesser extent, many patients with T2DM are interested in expanding their knowledge about their condition and one way to do so is by turning to the internet for information. However, in general, quality of the information about the T2DM available on the internet is poor taken in account the dissemination of patient-oriented evidence that matters ${ }^{34}$ which could induce to follow mistaken health habits as in other diseases. ${ }^{35}$
Another fact to consider when assessing the potential use of TM for the management of T2DM is the level of patient's use of ICTs. A recent study evaluated the relationship between HbAlc levels and the frequency with which patients with T2DM record and share their blood glucose levels with their physician. This study suggested that higher frequency in the recording of these levels did not correlate with a significant decrease in HbAlc levels, but recording and sharing with the physician did. ${ }^{36}$ In keeping with these findings, $85.9 \%$ and $14.4 \%$ of the patients who participated in our study recorded their blood glucose levels and other T2DM-related values, respectively. However, the percentage who shared these data with their doctor was $58.7 \%$. Fuji et al found that many patients felt that their doctor already had all the information necessary for the management of their

\begin{tabular}{|c|c|c|c|c|}
\hline \multirow[b]{2}{*}{ Website supervised by health professionals } & \multicolumn{2}{|c|}{ Not at all/little } & Indifferent & \multirow{2}{*}{$\begin{array}{l}\text { Quite a lot/a great deal } \\
70.6 \%\end{array}$} \\
\hline & $12.7 \%$ & $16.7 \%$ & i & \\
\hline $\begin{array}{r}\text { Web platform that allows you to communicate } \\
\text { with healthcare professionals }\end{array}$ & $7.8 \%$ & $21.6 \%$ & 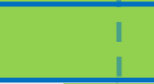 & $70.6 \%$ \\
\hline $\begin{array}{l}\text { Web platform that allows you to communicate } \\
\text { with other patients with similar health problems }\end{array}$ & $16.7 \%$ & $26.5 \%$ & I & $56.9 \%$ \\
\hline App for mobile devices & $9.8 \%$ & $19.6 \%$ & i & $70.6 \%$ \\
\hline $\begin{array}{r}\text { Reminders by SMS or WhatsApp sent from the } \\
\text { healthcare centre or the pharmacy }\end{array}$ & $9.8 \%$ & $23.5 \%$ & I & $66.7 \%$ \\
\hline
\end{tabular}

Figure 4 Patient's point of view: telemedicine (TM) resource preferences (patients with TM experience). 


\begin{tabular}{|c|c|c|c|}
\hline & Not at all/little & Indifferent & Quite a lot/a great deal \\
\hline Design & $29.4 \%$ & i & $64.7 \%$ \\
\hline Contents & $3.9 \% \quad 19.6 \%$ & I & $76.5 \%$ \\
\hline $\begin{array}{r}\text { Devices in which telemedicine resources are } \\
\text { available }\end{array}$ & $4.2 \% \quad 21.6 \%$ & $\perp$ & $74.5 \%$ \\
\hline Explanation about the program to facilitate its use & $4.9 \% 13.7 \%$ & $\begin{array}{l}\text { I } \\
\text { I }\end{array}$ & $78.4 \%$ \\
\hline $\begin{array}{r}\text { Access through technology devices at } \\
\text { the healthcare center }\end{array}$ & $3.9 \% \quad 23.5 \%$ & $\begin{array}{l}T \\
1 \\
\end{array}$ & $72.5 \%$ \\
\hline Interaction with the healthcare team & $2.9 \% 18.6 \%$ & $\begin{array}{l}1 \\
1\end{array}$ & $78.4 \%$ \\
\hline $\begin{array}{r}\text { Interaction with other patients with } \\
\text { similar health problems }\end{array}$ & $30.4 \%$ & T & $62.8 \%$ \\
\hline Time spent & $6.9 \% \quad 14.7 \%$ & I & $78.4 \%$ \\
\hline
\end{tabular}

Figure 5 Patient's point of view: items to be improved in telemedicine.

disease, which may explain why many of the patients who record these data do not share the information. It would therefore be important to stress how useful recording and sharing this type of data is and to promote and facilitate the use of the tools needed in order to do so. This may be particularly helpful in patients with a recent diagnosis of T2DM and in patients treated with insulin or oral antidiabetic drugs.

With regard to the clinical benefits of TM use, two recent meta-analyses have shown that, compared with usual care, TM helps to optimise glycaemic control by lowering HbAlc levels. ${ }^{13} 14$

For all that, beyond the objective results, adherence to this type of programme may be conditioned by patients' perceptions about the utility of TM. In this respect, consistent with our results, a European study conducted with $>2000$ patients in nine countries suggested that patients perceived TM to be a useful tool for improving management of their disease by saving time in unnecessary commutes. ${ }^{37}$ In young patients, where hospital attendance may be hampered by working time constraints, TM may be particularly advantageous. With regard to TM resources, Faruque et al found that TM programmes that used online platforms and text messages that allowed patient-physician communication were significantly more effective at glycaemic control (HbAlc levels) by allowing treatment to be adjusted. ${ }^{13}$ This was one of the types of platform that aroused most interest in the patients surveyed in our study. These results are in line with the results obtained in a qualitative study that evaluated the implementation of a TM programme for patients with T2DM, which found that interaction with the physician was highly valued by the patients. ${ }^{38}$

The level of satisfaction with TM that was observed in our study is comparable to that seen in previous studies.
In one of these, the level of satisfaction of patients who had participated in TM programmes conducted in six health centres in the Albacete healthcare region, was high or very high in $96 \%$ of cases. ${ }^{20}$ Similarly, another study found that patients' acceptance was 5.8 (IQR 5.2-6) on a scale from 1 to $6 .^{37}$

Despite the high level of satisfaction reported in our study, the majority of the patients indicated that in order to promote TM use, some aspects such as providing programmes with simple instructions, quickly record and transfer data and the availability of the information recorded should be improved. In line with these results, Koopman et alalso identified the demand for simple strategies that are technically stable and easily adapted to daily routines. ${ }^{38}$ Similarly, availability of the data recorded is in high demand by patients who record their disease-related data. $^{437}$

The profile of patients who are interested in participating in TM programmes is that of a middle-aged male patient, who is in a partnership, has a higher education and is in active employment. From an economic point of view, it has been suggested that the benefit of TM interventions is especially relevant to patients who reside in areas that are far from their healthcare centre ${ }^{3940}$ and who are typically elderly. However, whereas older patients are less accustomed to recording information using digital formats, investment in especially simple and/ or automated technological resources together with greater training in their use could contribute to improve the willingness of elderly patients to participate in TM programmes.

Finally, the study data reveal how low the implementation and promotion of the use of TM for the management of T2DM are in Spain. In this sense, physicians and pharmacists would have a very important role in promoting its 
use and identifying which TM resources are best for each patient.

This study shows limitations inherent in its observational design, including susceptibility to bias and confounding, which restrict the ability to define causality. ${ }^{41}$ In addition, the results must be interpreted while keeping in mind that all of the issues evaluated, including those related to the patient's clinical situation, are always expressed from the patient's point of view, which increases the possibility that the issues raised here may have different interpretations. Furthermore, snowball technique could lead to potential sampling bias and low sample representativeness. Nevertheless, the wide sample variability observed (clinical and sociodemographic) suggests a limited bias.

\section{CONCLUSION}

In Spain, nearly $10 \%$ of patients with T2DM have experience with TM and it is well accepted, especially the one based on glucometers. Although the use of TM has been found to offer numerous benefits in the management of T2DM, its implementation and promotion is scant, especially among the elderly. Simple resources, allowing treatment-related data to be recorded as well as providing hygiene and nutrition tips, enabling the adjustment of treatment and the exchange of information with the medical team, stand out as the most suitable for the management of T2DM.

\section{Author affiliations}

${ }^{1}$ Medical Department, Mylan, Madrid, Spain

${ }^{2}$ DAP-Cat group. Unitat de Suport a la Recerca Barcelona Ciutat, Institut Universitari d'Investigació en Atenció Primària Jordi Gol (IDIAP Jordi Gol), Barcelona, Spain ${ }^{3}$ Primary Health Care Center Raval Sud, Gerència d'Àmbit d'Atenció Primària Barcelona Ciutat, Institut Català de la Salut, Barcelona, Spain

${ }^{4}$ Coordinator Working Group on Diabetes SEFAC Pontevedra, Spain

${ }^{5}$ Universidad de Granada, Granada, Spain

${ }^{6}$ Outcomes'10, Castellon, Spain

Acknowledgements The authors would like to thank the patients who participated in this study. The authors would also like to thank Ana López (Assistant from Mylan Medical Department) and Miriam Prades (HE\&OR Manager from Outcomes'10) for their assistance in the study.

Contributors This article is part of a Doctoral Thesis of PR-F on behalf of the Doctoral Programme in Pharmacy, University of Granada (Spain). All authors have contributed in all the tasks of the study (design, start-up, analysis of the results and manuscript elaboration).

Funding The study was sponsored by BGP Products Operations SL (Mylan). JF-N, JAF-P and FM-M state they have no conflict of interest. PR-F and MLO-P work at BGP Products Operations SL (Mylan). HDdeP works for an independent research organisation (Outcomes'10), which has received fees for its contribution to the development and coordination of the project and to the writing of this manuscript.

Disclaimer The funding source had no role in the design, conduct or reporting of the study.

Competing interests None declared.

Patient consent for publication Not required.

Ethics approval The study protocol was approved by the ethics committee of the 'Hospital Universitario Puerta de Hierro' (Madrid, Spain).

Provenance and peer review Not commissioned; externally peer reviewed. Data sharing statement No unpublished data for this article are available.
Open access This is an open access article distributed in accordance with the Creative Commons Attribution Non Commercial (CC BY-NC 4.0) license, which permits others to distribute, remix, adapt, build upon this work non-commercially, and license their derivative works on different terms, provided the original work is properly cited, appropriate credit is given, any changes made indicated, and the use is non-commercial. See: http://creativecommons.org/licenses/by-nc/4.0/.

\section{REFERENCES}

1. Soriguer F, Goday A, Bosch-Comas A, et al. Prevalence of diabetes mellitus and impaired glucose regulation in Spain: the Di@bet.es Study. Diabetologia 2012;55:88-93.

2. Guariguata L, Whiting DR, Hambleton I, et al. Global estimates of diabetes prevalence for 2013 and projections for 2035. Diabetes Res Clin Pract 2014;103:137-49.

3. Christensen K, Doblhammer G, Rau R, et al. Ageing populations: the challenges ahead. Lancet 2009;374:1196-208.

4. Fuji KT, Abbott AA, Galt KA. A qualitative study of how patients with type 2 diabetes use an electronic stand-alone personal health record. Telemed J E Health 2015;21:296-300.

5. Bashshur RL, Shannon GW, Smith BR, et al. The empirical evidence for the telemedicine intervention in diabetes management. Telemed $J$ E Health 2015;21:321-54.

6. Lim D, Oakley AM, Rademaker M. Better, sooner, more convenient: a successful teledermoscopy service. Australas J Dermatol 2012;53:22-5.

7. Caffery LJ, Farjian M, Smith AC. Telehealth interventions for reducing waiting lists and waiting times for specialist outpatient services: A scoping review. J Telemed Telecare 2016;22:504-12.

8. Capoccia K, Odegard P, Letassy N. Medication adherence with diabetic medication. Diabetes Educ 2015. Available: http://tde. sagepub.com/content/early/2015/12/03/0145721715619038.long

9. Hamine S, Gerth-Guyette E, Faulx D, et al. Impact of mHealth chronic disease management on treatment adherence and patient outcomes: a systematic review. J Med Internet Res 2015;17:e52.

10. Anglada-Martinez $\mathrm{H}$, Riu-Viladoms G, Martin-Conde M, et al. Does mHealth increase adherence to medication? Results of a systematic review. Int J Clin Pract 2015;69:9-32.

11. Di Cerbo A, Morales-Medina JC, Palmieri B, et al. Narrative review of telemedicine consultation in medical practice. Patient Prefer Adherence 2015;9:65-75.

12. Ciemins $E$, Coon P, Peck R, et al. Using telehealth to provide diabetes care to patients in rural Montana: findings from the promoting realistic individual self-management program. Telemed $J E$ Health 2011;17:596-602.

13. Faruque LI, Wiebe N, Ehteshami-Afshar A, et al. Effect of telemedicine on glycated hemoglobin in diabetes: a systematic review and meta-analysis of randomized trials. CMAJ 2017;189:E34 $1-\mathrm{E} 364$.

14. Su D, Zhou J, Kelley MS, et al. Does telemedicine improve treatment outcomes for diabetes? A meta-analysis of results from 55 randomized controlled trials. Diabetes Res Clin Pract 2016;116:136-48.

15. Wayne N, Perez DF, Kaplan DM, et al. Health Coaching Reduces $\mathrm{HbA1c}$ in Type 2 Diabetic Patients From a Lower-Socioeconomic Status Community: A Randomized Controlled Trial. J Med Internet Res 2015;17:e224.

16. Crowley MJ, Edelman D, McAndrew AT, et al. Practical Telemedicine for Veterans with Persistently Poor Diabetes Control: A Randomized Pilot Trial. Telemed J E Health 2016;22:376-84.

17. Kuo A, Dang S. Secure Messaging in Electronic Health Records and Its Impact on Diabetes Clinical Outcomes: A Systematic Review. Telemed J E Health 2016;22:769-77.

18. Rasmussen OW, Lauszus FF, Loekke M. Telemedicine compared with standard care in type 2 diabetes mellitus: A randomized trial in an outpatient clinic. J Telemed Telecare 2016;22:363-8.

19. Quinn CC, Khokhar B, Weed K, et al. Older Adult Self-Efficacy Study of Mobile Phone Diabetes Management. Diabetes Technol Ther 2015;17:455-61.

20. López-Torres J, Rabanales J, Fernández R, et al. Results of a telemedicine program for primary care patients with type 2 diabetes [Resultados de un programa de telemedicina para pacientes con diabetes tipo 2 en atención primaria]. Gac Sanit 2015;29:55-8.

21. Pérez-Ferre N, Galindo M, Fernández MD, et al. A Telemedicine system based on Internet and short message service as a new approach in the follow-up of patients with gestational diabetes. Diabetes Res Clin Pract 2010;87:e15-e17.

22. Peña NV, Torres M, Cardona JA, et al. Impact of telemedicine assessment on glycemic variability in children with type 1 diabetes mellitus. Diabetes Technol Ther 2013;15:136-42. 
23. Azar M, Gabbay R. Web-based management of diabetes through glucose uploads: has the time come for telemedicine? Diabetes Res Clin Pract 2009;83:9-17.

24. Rojahn K, Laplante S, Sloand J, et al. Remote Monitoring of Chronic Diseases: A Landscape Assessment of Policies in Four European Countries. PLoS One 2016;11:e0155738.

25. Klonoff DC. Telemedicine for Diabetes. J Diabetes Sci Technol 2016;10:3-5.

26. Shahrokni A, Mahmoudzadeh S, Saeedi R, et al. Older People with Access to Hand-Held Devices: Who Are They? Telemedicine and e-Health 2015;21:550-6.

27. Goodman LA. Snowball sampling. Ann Math Stat 1961;32:148-70.

28. Instituto nacional de estadística. Cifras de población (>18) [Internet]. 2015. Available: http://www.ine.es/jaxiT3/Datos.htm?t=9663 (cited 1 Nov 2015).

29. Czaja SJ, Lee CC. Information technology and older adults. In: Sears A, Jacko J, eds. Human-Computer Interaction: Designing for Diverse Users and Domains, 2009:18-30.

30. Insituto Nacional de Estadística. Encuesta sobre equipamiento y uso de tecnologías de información y comunicación en los hogares. In: INEbase [Internet]. 2016. Available: http://www.ine.es/dyngs/ INEbase/es/operacion.htm?c=Estadistica_C\&cid=1254736176741\& menu=ultiDatos\&idp=1254735976608 (cited 1 Feb 2017).

31. Ortego Centeno N, Callejas Rubio JL, Benticuaga Martínez MN, et al. Utilización de Internet como fuente de información por los pacientes de una consulta de Enfermedades Autoinmunes Sistémicas. Revista Clínica Española 2005;205:255-8

32. Ortego Centeno N, Barnosi Marín AC, Simeón Aznar CP, et al. Búsqueda de información en Internet por parte de pacientes de diferentes Comunidades Autónomas con enfermedades autoinmunitarias crónicas. Medicina Clínica 2009;133:467-71.

33. Kalantzi S, Kostagiolas P, Kechagias G, et al. Information seeking behavior of patients with diabetes mellitus: a cross-sectional study in an outpatient clinic of a university-affiliated hospital in Athens, Greece. BMC Res Notes 2015;8:48.

34. Giménez-Pérez G, Caixàs A, Giménez-Palop O, et al. Dissemination of 'patient-oriented evidence that matters' on the Internet: the case of Type 2 diabetes treatment. Diabet Med 2005;22:688-92.

35. Zhang D, Schumacher C, Harris MB, et al. The Quality and Readability of Information Available on the Internet Regarding Lumbar Fusion. Global Spine J 2016;6:133-8.

36. Chow N, Shearer D, Aydin Plaa J, et al. Blood glucose selfmonitoring and internet diabetes management on A1C outcomes in patients with type 2 diabetes. BMJ Open Diabetes Res Care 2016;4:e000134.

37. Dario C, Luisotto E, Dal Pozzo E, et al. Assessment of Patients Perception of Telemedicine Services Using the Service User Technology Acceptability Questionnaire. Int J Integr Care 2016;16:13-14.

38. Koopman RJ, Wakefield BJ, Johanning JL, et al. Implementing home blood glucose and blood pressure telemonitoring in primary care practices for patients with diabetes: lessons learned. Telemed J E Health 2014;20:253-60.

39. Fountoulakis S, Papanastasiou L, Gryparis A, et al. Impact and duration effect of telemonitoring on $\mathrm{HbA} 1 \mathrm{c}, \mathrm{BMI}$ and cost in insulin-treated Diabetes Mellitus patients with inadequate glycemic control: A randomized controlled study. Hormones 2015;14:632-43.

40. Chérrez-Ojeda I, Vanegas E, Calero E, et al. What Kind of Information and Communication Technologies Do Patients with Type 2 Diabetes Mellitus Prefer? An Ecuadorian Cross-Sectional Study. Int J Telemed Appl 2018;2018:1-8.

41. Yang W, Zilov A, Soewondo P, et al. Observational studies: going beyond the boundaries of randomized controlled trials. Diabetes Res Clin Pract 2010;88 Suppl 1:S3-S9. 